\title{
A prospective study of the incidence, associations and outcomes of ocular surface squamous neoplasia in the United Kingdom
}

\author{
Christine A. Kiire ${ }^{1}$ Rosalind M. K. Stewart ${ }^{2,3} \cdot$ Sathish Srinivasan ${ }^{4,5} \cdot$ Heinrich Heimann ${ }^{2,3} \cdot$ Stephen B. Kaye ${ }^{2,3}$. \\ Baljean Dhillon $\mathbb{1}^{6}$
}

Received: 21 January 2018 / Revised: 17 June 2018 / Accepted: 19 July 2018 / Published online: 28 December 2018

(c) The Royal College of Ophthalmologists 2018

\section{Learning Objectives}

Upon completion of this activity, participants will be able to:

1. Assess the incidence and demographic profile of patients presenting with OSSN in the United Kingdom during a 12month period, based on a prospective observational study.

2. Evaluate the clinical presentation of and risk factors associated with OSSN in the United Kingdom during a 12-month period, based on a prospective observational study.

3. Determine management and prognosis of OSSN in the UK during a 12-month period, based on a prospective observational study.

\section{Continuing Medical Education}

In support of improving patient care, this activity has been planned and implemented by Medscape, LLC and Springer Nature. Medscape, LLC is jointly accredited by the Accreditation Council for Continuing Medical Education (ACCME), the Accreditation Council for Pharmacy Education (ACPE), and the American Nurses Credentialing Center (ANCC), to provide continuing education for the healthcare team.

Medscape, LLC designates this Journal-based CME activity for a maximum of 1.00 AMA PRA Category 1 Credit(s). Physicians should claim only the credit commensurate with the extent of their participation in the activity.

All other clinicians completing this activity will be issued a certificate of participation. To participate in this journal CME activity: (1) review the learning objectives and author disclosures; (2) study the education content; (3) take the post-test with a $75 \%$ minimum passing score and complete the evaluation at www.medscape.org/journal/eye; (4) view/print certificate.

\section{Credit hours}

1.0

Release date: 28 December 2018;

Expiration date: 28 December 2019

Post-test link: https://medscape.org/eye/posttest902113

Supplementary information The online version of this article (https:// doi.org/10.1038/s41433-018-0217-x) contains supplementary material, which is available to authorized users.

$\triangle$ Christine A. Kiire

christine.kiire@ouh.nhs.uk

1 Oxford Eye Hospital, John Radcliffe Hospital, Oxford University Hospitals NHS Foundation Trust, Oxford, UK

2 St Paul's Eye Unit, Royal Liverpool and Broadgreen University Hospitals NHS Trust, Liverpool, UK Medscape

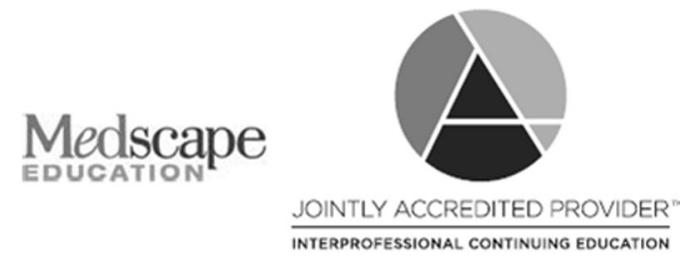

3 Department of Eye and Vision Science, Institute of Ageing and Chronic Disease, University of Liverpool, Liverpool, UK

4 Department of Ophthalmology, University Hospital Ayr, Ayr, UK

5 University of Glasgow, Glasgow, Scotland, UK

6 School of Clinical Sciences, University of Edinburgh, Edinburgh, UK 


\title{
Authors/Editor disclosure information
}

Sobha Sivaprasad has disclosed the following relevant financial relationships: Served as an advisor or consultant for Allergan, Bayer, Boehringer Ingelheim, Novartis, Heidelberg, Optos. Served as a speaker or a member of a speakers bureau for Bayer, Allergan, Novartis, Optos. Received grants for clinical research from Bayer, Boehringer Ingelheim, Allergan, Novartis, Optos. H.H. has disclosed the following relevant financial relationships: Served as a speaker or a member of a speakers bureau for Alcon, Alimera, Bausch and Lomb, Bayer AG. C.A.K., R.M.K.S., S.S., S.B.K., and B.D. have disclosed no relevant financial relationships.

\section{Journal CME author disclosure information}

Laurie Barclay has disclosed the following relevant financial relationships: Owns stock, stock options, or bonds from: Pfizer Inc.

\begin{abstract}
Purpose To describe the incidence, associations and outcomes of ocular surface squamous neoplasia (OSSN) in the United Kingdom.

Methods Prospective, observational study of every new case of OSSN reported via the British Ophthalmological Surveillance Unit reporting scheme over a 12-month period. Cases were followed up for 12 months.

Results The reported incidence of OSSN was 0.53 cases/million/year (conjunctival intraepithelial neoplasia: 0.43 cases/ million/year; squamous cell carcinoma: 0.08 cases/million/year). Eighty-five per cent of affected patients were male, $97 \%$ were Caucasian, and the mean age at presentation was $67.9( \pm 12.8)$ years. Information on potential underlying risk factors was frequently unknown. The most commonly affected sites were the limbus and the nasal and temporal bulbar conjunctivae. Most patients presented with a visual acuity of 6/9 or better, without symptoms of pain or visual loss. Excision (with or without additional treatment) was the most common first-line treatment and interferon (with or without additional treatment) was the most common second-line treatment, although management varied widely. Complications of treatment were rare but occasionally severe. Recurrence within 12 months of follow-up occurred in at least $6 \%$ of patients.

Conclusion Although subject to reporting bias, these data suggest that there has not been a significant change in the incidence of OSSN in the United Kingdom, or its demographic profile, since 1996. The broad range of management approaches identified in this study reflect a lack of consensus as to the optimal referral and treatment pathways.
\end{abstract}

\section{Introduction}

Ocular surface squamous neoplasia (OSSN) is classically divided into conjunctival intraepithelial neoplasia (CIN) and squamous cell carcinoma (SCC). CIN is dysplasia of the ocular surface epithelium that has not yet invaded the substantia propria of the conjunctiva or Bowman layer of the cornea [1, 2]. It causes disfigurement and has the potential to progress to SCC, which may cause severe disability [2].

Most of the advances in our understanding of the incidence, diagnosis and treatment of OSSN have taken place in the last 20 years [3, 4]. Globally, the incidence of OSSN has been estimated to range between fewer than 0.2 cases/million/year (UK, 1996) [5] and 35 cases/million/year (Uganda, 1992) [6]. Age-standardised incidence rates, which make adjustments for population structure, have also been calculated using data from the International Agency for Research on Cancer. Using these data, covering the period from 1998 to 2002, Gichuhi et al. [7] found a mean age-standardised worldwide incidence of ocular SCC (principally tumours of the conjunctiva and cornea) of 1.8
(95\% confidence interval: 0.9 to 2.6 ) cases/million/year among males and 0.8 (95\% confidence interval: 0.1 to 1.5 ) cases/million/year among females. OSSN is on the increase in Africa [6, 8], but has been detected all around the world [7, 9]. In 2003, the balance of epidemiological evidence suggested that the highest risk of OSSN was in older Caucasian men, particularly those living closer than 30 degrees latitude to the equator [10]. It is possible that this remains the case in the West. In Africa, however, OSSN has been affecting younger people with more aggressive tumours [11]. OSSN is more common in Africa than anywhere else, and unlike on other continents, it affects males and females equally there [7].

There appears to be an important association between human immunodeficiency virus (HIV) seropositivity and OSSN [3, 12-25]. Patients presenting with OSSN might therefore benefit from HIV testing. To date, most published studies of the association between HIV seropositivity and OSSN have taken place in Africa, Asia and North America (USA). Other potential risk factors or associations include human papilloma virus (HPV) infection; [17, 24, 26] sunlight exposure [23, 24, 27], which can lead to mutations in the 
tumour suppressor gene p53; [28] p63, a homologue of p53; [29, 30] smoking; [24, 31] immunosuppression; [32-34] and xeroderma pigmentosa $[35,36]$. There have also been suggestions of a possible association between OSSN and atopic keratoconjunctivitis [23, 32, 37-39]. A larger tumour size might be predictive of invasive SCC or risk of recurrence [40, 41].

We set out to describe the incidence, associations and outcomes of OSSN in the UK over a particular 12-month period. Specifically, we sought to answer the following research questions:

- What is the incidence of OSSN?

- What is the demographic profile of patients presenting with OSSN?

- What risk factors are associated with OSSN?

- How does OSSN present?

- How is OSSN currently being managed?

- Is there any evidence of recurrence of OSSN over a 12month follow-up period?

\section{Material and methods}

This study was conducted in accordance with the principles of the Declaration of Helsinki. Ethical approval was sought and obtained from Oxford C NHS Research Ethics Committee.

\section{Study design}

This is a prospective, observational study in which we set out to identify each new case of OSSN in the UK over a 12month period. Cases were followed up for 12 months.

\section{Setting}

Cases of OSSN were identified through the Royal College of Ophthalmologists' British Ophthalmological Surveillance Unit (BOSU) reporting system [42]. Briefly, using the BOSU system, the study investigators received notification as to which ophthalmologists had reported seeing a case of OSSN. Direct contact was then made with the reporting ophthalmologist, using a questionnaire to collect information about the reported case. This included information to confirm the patient's eligibility for inclusion in the study. A follow-up questionnaire was sent out 12 months later. The questionnaires were completed by the reporting ophthalmologists. Study investigators did not make direct contact with the patients. All further reference to reporting ophthalmologists in this report refers to the UK ophthalmologists who reported cases of OSSN via the BOSU, and not specifically to the study investigators.

\section{Participants}

The patients eligible to contribute to this study were those with a new, histologically confirmed diagnosis of OSSN that was made between the 8th of August 2013 and the 8th of August 2014. Bilateral lesions were counted as two separate cases. Recurrences were recorded on the follow-up questionnaire at 12 months, and not as new cases.

\section{Data sources}

All data were obtained via baseline and 12-month follow-up questionnaires, the details of which are contained in the Supplementary Information.

\section{Bias}

This study depended on voluntary reporting of new cases of OSSN by consultant ophthalmologists and associate specialists in the UK. As such, it was subject to reporting bias, with information only available on cases that were reported, and no scope for identifying clinico-pathological features of cases that were not reported.

\section{Statistical methods}

This is largely a descriptive study. The incidence of OSSN in the UK was calculated as the number of cases/million/ year. Analysis of lesion location was performed using a Kruskal-Wallis one-way analysis of variance test for nonparametric data.

\section{Results}

\section{Participants}

Sixty-one cases of OSSN in 60 patients were reported via the BOSU scheme. Seven were excluded because they did not fall within the inclusion dates for the study, and three were excluded because they had the wrong diagnosis. There was one duplicate and there were three instances where the patient details were not recalled or traceable by the reporting ophthalmologist. After initially reporting cases of OSSN to the BOSU, 13 questionnaires were not returned by the reporting ophthalmologists. This left a total of 34 cases (in 33 patients) for which we had baseline data.

Twelve-month follow-up data were only available for 24 of the original 34 cases. This included bilateral OSSN in one patient. Eight patients had been lost to follow-up and two were deceased. Data regarding cause of death (where applicable) were unavailable. 


\section{Outcome data}

\section{The estimated incidence of ocular surface squamous neoplasia in the UK}

With 34 confirmed cases of OSSN reported via the BOSU scheme between the 8th of Aug 2013 and the 8th of August 2014, the estimated incidence of this condition in the UK is calculated as 0.53 cases/million/year (CIN: 0.43 cases/million/year; SCC: 0.08 cases/million/year).

The demographic profile of patients presenting with ocular surface squamous neoplasia in the UK

Table 1 provides a summary of the demographic profile of eligible participants. OSSN cases that were reported as "SCC in situ" were classified as CIN for the purpose of this table. CIN was 5.6 times as common as SCC in our dataset. The majority of patients were male (85\%), and the mean age of the patients affected was in the seventh decade. All patients were reported to be Caucasian, apart from one person who was of Asian origin and one person for whom ethnicity data were missing.

\section{Risk factors associated with ocular surface squamous neoplasia in this study}

In addition to patient demographics, Table 1 contains some information regarding some of the well-known risk factors for OSSN, as recorded on the baseline questionnaires. Smoking history and HIV and HPV status were frequently unknown.

\section{How ocular surface squamous neoplasia presented}

The mean length of time to diagnosis was over 235 days ( 7.7 months) from presentation. There was, however, a very wide spread of this data, with a range from 4 days to 1391 days. Half of the reporting ophthalmologists were seeing patients who had been referred to them from elsewhere, often from another hospital, but occasionally from another ophthalmologist within their department.

Table 2 is a summary of the reported symptoms and signs of OSSN at presentation. The majority of patients presented with visual acuity of 6/9 or better, and without symptoms of pain or loss of vision. In the 10 cases where visual acuity was recorded as below 6/9, seven reports attributed the loss of vision, at least in part, to OSSN. Of these, two cases were thought to be due to a combination of OSSN and another ocular comorbidity. One case occurred in an anophthalmic socket.

Figure 1 illustrates the distribution of the OSSN cases that were reported. The most commonly affected site for the
OSSN lesion was the limbus, followed by the nasal bulbar conjunctiva and then the temporal bulbar conjunctiva. The maximum diameter of the lesions ranged from 3 to $20 \mathrm{~mm}$ (mean $7.5 \mathrm{~mm}$ ).

There was no significant difference in the laterality of lesions (involvement of right eye or left eye) $(p=0.24)$. Lesions on the right eye were, however, significantly larger in maximum diameter than those on the left eye $(8.42 \mathrm{~mm}$ (SD $4.47 \mathrm{~mm}$ ) versus $5.85 \mathrm{~mm}$ (SD $2.65 \mathrm{~mm}), p=0.01$ ), but not of higher histopathological grade $(p=0.30)$.

Table 1 Summary of demographic information and comorbidities in reported cases of ocular surface squamous neoplasia

\begin{tabular}{|c|c|}
\hline Selected characteristic & $\begin{array}{l}N(\%) \text { or mean } \\
(\mathrm{SD})\end{array}$ \\
\hline $\begin{array}{l}\text { Number of eligible cases of OSSN with baseline data } \\
\text { available for analysis }\end{array}$ & $34(100 \%)$ \\
\hline $\begin{array}{l}\text { Number of patients with OSSN with baseline data } \\
\text { available for analysis }\end{array}$ & $33(100 \%)$ \\
\hline \multicolumn{2}{|l|}{ OSSN sub-classification } \\
\hline $\mathrm{CIN}$ & $28(82 \%)$ \\
\hline SCC & $5(15 \%)$ \\
\hline Other (specify) & $1(3 \%)$, "OSSN" \\
\hline Length of time to diagnosis (days) & $235.1(332.5)$ \\
\hline Age (years) & $67.9(12.8)$ \\
\hline \multicolumn{2}{|l|}{ Sex } \\
\hline Male & $28(85 \%)$ \\
\hline Female & $4(12 \%)$ \\
\hline Not recorded & $1(3 \%)$ \\
\hline \multicolumn{2}{|l|}{ Race } \\
\hline Caucasian & $32(97 \%)$ \\
\hline Other (specify) & $1(3 \%)$, Asian \\
\hline Unknown & $1(3 \%)$ \\
\hline \multicolumn{2}{|l|}{ Smoking status } \\
\hline Never smoked & $14(42 \%)$ \\
\hline Ex-smoker & $3(9 \%)$ \\
\hline Current smoker & $3(9 \%)$ \\
\hline Unknown & $13(39 \%)$ \\
\hline \multicolumn{2}{|l|}{ Immunosuppression } \\
\hline Current & $2(6 \%)$ \\
\hline Previous & $1(3 \%)$ \\
\hline None & $30(91 \%)$ \\
\hline Unknown & $0(0 \%)$ \\
\hline \multicolumn{2}{|l|}{ HIV status } \\
\hline Positive & $0(0 \%)$ \\
\hline Negative & $5(15 \%)$ \\
\hline Unknown & $28(85 \%)$ \\
\hline \multicolumn{2}{|l|}{ HPV status } \\
\hline Positive & $2(6 \%)$ \\
\hline Negative & $6(18 \%)$ \\
\hline Unknown & $25(76 \%)$ \\
\hline \multicolumn{2}{|l|}{ Xeroderma pigmentosa } \\
\hline Present & $0(0 \%)$ \\
\hline Absent & $32(97 \%)$ \\
\hline Unknown & $1(3 \%)$ \\
\hline
\end{tabular}

OSSN Ocular surface squamous neoplasia, CIN conjunctival intraepithelial neoplasia, SCC squamous cell carcinoma, HIV human immunodeficiency virus, $H P V$ human papilloma virus 


\section{Management of ocular surface squamous neoplasia}

The management options chosen by the reporting ophthalmologists were varied and are shown in Table 3. The initial choice of treatment given by reporting ophthalmologist was influenced by prior treatments, if given, and whether or not the patient was subsequently going to be referred elsewhere for ongoing care. Of the seven patients who appear to have had either no treatment, a biopsy and lymph node fine needle aspiration, or topical antibiotics prescribed by the reporting ophthalmologist, two had undergone excision of the OSSN lesion (one with cryotherapy) prior to seeing the reporting ophthalmologist, and the other five were referred to ocular oncology units for treatment.

Overall, excision was one of the most common first-line treatments provided, either alone or in combination with other treatments. No adjunctive tests were requested by the reporting ophthalmologist in $65 \%$ of cases. Of the 11 cases (32\%) referred elsewhere for ongoing management, 10 of these went to three of the UK national ocular oncology centres, and in one case a referral was made for shared care with a specialist oculoplastics unit.

\section{Outcomes following treatment for ocular surface squamous neoplasia}

At 12 months, 18 cases were confirmed as still being under active follow-up with the reporting ophthalmologist. Five out of nine patients who had previously been referred to a tertiary centre for ongoing care, and had follow-up data, had been discharged back to secondary care. All of these patients had a diagnosis of CIN. None of the patients received a change in their OSSN diagnosis over the study period, but one patient who was receiving immunosuppressive treatment had a biopsy that was positive for ocular mucous membrane pemphigoid taken from the same eye.

Table 4 is a summary of the management of the OSSN cases in the 12 months between the baseline questionnaire and the follow-up questionnaire, and the associated clinical outcomes. In five of the cases where participants had a visual acuity level of $6 / 12$ or below, the cause of reduced vision was thought to be a comorbidity unrelated to OSSN.

One-third of the patients with follow-up data available had received additional treatment following their first-line treatment. This proportion excludes three patients who were referred to ocular oncology units without receiving prior definitive treatment from the ophthalmologists who completed the baseline questionnaire. As with many of the cases that had the type of treatment given recorded on the baseline questionnaire, these three received primary excision of the OSSN lesion. In their cases, it was combined with either 5fluorouracil or plaque radiotherapy. Review of all the follow-up questionnaires showed that interferon was the
Table 2 Presenting features of ocular surface squamous neoplasia cases

\begin{tabular}{|c|c|}
\hline Presenting feature & $N(\%)$ or mean $(\mathrm{SD})$ \\
\hline \multicolumn{2}{|l|}{ Eye affected } \\
\hline Right & $20(59 \%)$ \\
\hline Left & $14(41 \%)$ \\
\hline \multicolumn{2}{|l|}{ BCVA (Snellen) } \\
\hline $6 / 6$ or better & $18(53 \%)$ \\
\hline $6 / 7.5$ & $1(3 \%)$ \\
\hline $6 / 9$ & $5(15 \%)$ \\
\hline $6 / 12$ & $2(6 \%)$ \\
\hline $6 / 18$ & $2(6 \%)$ \\
\hline $6 / 24$ & $3(9 \%)$ \\
\hline $6 / 36$ & $1(3 \%)$ \\
\hline $6 / 60$ or worse & $2(6 \%)$ \\
\hline \multicolumn{2}{|l|}{ Presenting symptoms } \\
\hline Incidental finding & $10(29 \%)$ \\
\hline Lump on eye & $12(35 \%)$ \\
\hline Redness of the eye & $11(32 \%)$ \\
\hline Irritation of eye & $7(21 \%)$ \\
\hline Pain in eye & $3(9 \%)$ \\
\hline Loss of vision & $3(9 \%)$ \\
\hline \multicolumn{2}{|l|}{ Site involved ${ }^{\mathrm{a}}$} \\
\hline \multicolumn{2}{|l|}{ Bulbar conjunctiva } \\
\hline Superior & $0(0 \%)$ \\
\hline Nasal & $15(44 \%)$ \\
\hline Inferior & $7(21 \%)$ \\
\hline Temporal & $11(32 \%)$ \\
\hline \multicolumn{2}{|l|}{ Tarsal conjunctiva } \\
\hline Superior & $1(3 \%)$ \\
\hline Inferior & $4(12 \%)$ \\
\hline Limbus & $19(56 \%)$ \\
\hline \multicolumn{2}{|l|}{ Cornea } \\
\hline Superior & $0(0 \%)$ \\
\hline Nasal & $2(6 \%)$ \\
\hline Inferior & $6(18 \%)$ \\
\hline Temporal & $6(18 \%)$ \\
\hline Other (state) & 1 (3\%), "plica, fornix" \\
\hline Maximum diameter (mm) & $7.5(4.0)$ \\
\hline
\end{tabular}

BCVA Best-corrected visual acuity

${ }^{\mathrm{a}}$ Lesions may have extended to involve more than one site

most commonly given second-line treatment. In this study, it only seemed to be given within a tertiary care setting. The patients who received it had a diagnosis of CIN, and in a majority of cases had received primary treatment with excision, or biopsy and 5-fluorouracil.

Complications of OSSN treatment were rare and are shown in Table 4 . Over $40 \%$ of patients were reported to have no abnormalities detected at their 12-month review, but scarring was not uncommon. One patient with no history of ocular mucous membrane pemphigoid had developed symblepharon. The two confirmed recurrences of CIN occurred on the nasal conjunctiva, in patients who had extensive lesions (inferonasal bulbar conjunctiva, limbus and inferior tarsal conjunctiva; inferonasal bulbar 

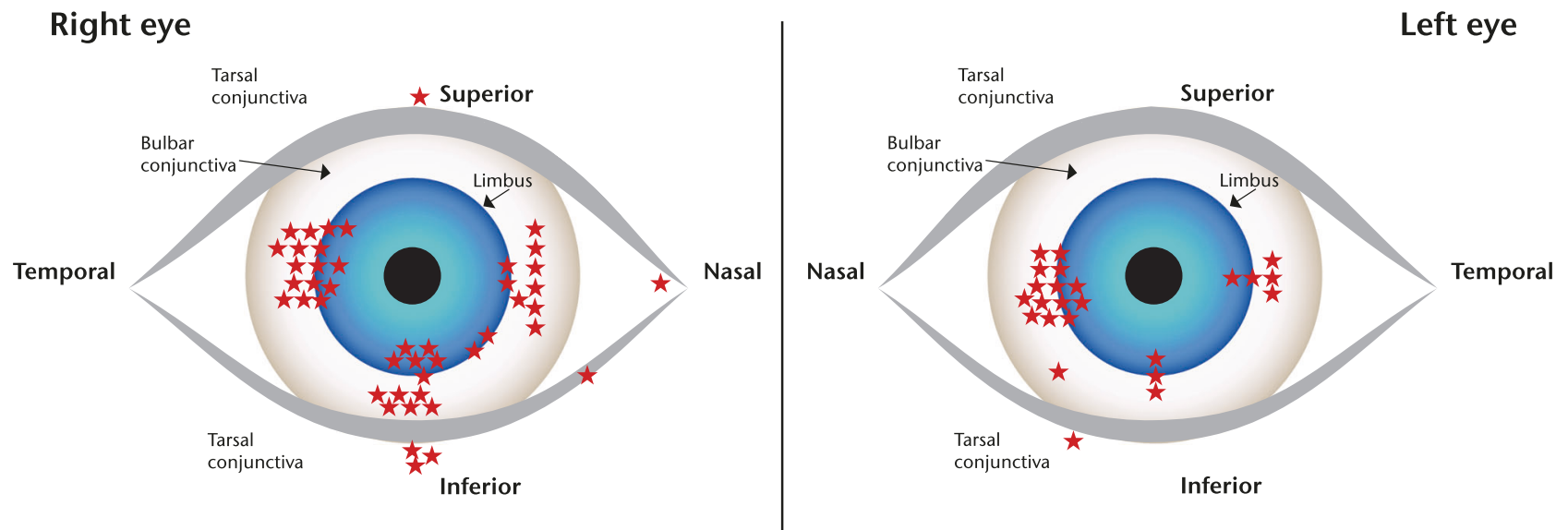

Fig. 1 Stars indicate the approximate location of the affected sites. Most lesions involved more than one site. In these cases, each site mentioned by the reporting ophthalmologist was marked

conjunctiva, fornix and plica) at baseline. One had previously been immunosuppressed, and had been treated with multiple excisions and 5-fluorouracil, and more of this treatment was planned for the recurrence. The other patient with a recurrence had been treated with topical steroids followed by interferon and then mitomycin-C. There were plans to treat this recurrence with excision and cryotherapy.

Most patients had further follow-up planned for 3-6 months' time. Where this was not the case, time to follow-up was strongly determined by the perceived risk of vision loss (e.g. due to corneal abnormalities) or recurrence.

\section{Discussion}

The estimated UK incidence of OSSN ( 0.53 cases/million/ year), as calculated in this study, is significantly below the mean incidence of OSSN calculated over a 10 year period, before 1992, in Brisbane, Australia (19 cases/million/year) [43]. The incidence of SCC in this study $(0.08 \mathrm{cases} / \mathrm{mil}-$ lion/year) falls within the level that was estimated for the UK by Newton et al. [5] in 1996 ( $<0.2$ cases/million/year). Given the probable high rate of underreporting via the BOSU scheme, as suggested by a paucity of cases reported from some of the national ocular oncology units, this is likely to be lower than the true incidence of this condition in the UK.

If we were to assume that the UK national ocular oncology centres that did not report any cases via the BOSU saw a similar number of OSSN patients to the number reported by Maudgil et al. [41] in their retrospective review of the case notes, clinical photographs, and histopathology reports of 78 patients with OSSN who were managed in their unit between 1994 and 2010 and published in 2013 ( $\sim 4.9$ cases per year, of which $\sim 20 \%$ were SCC), then the UK incidence of this condition would rise to 0.76 cases/ million/year (CIN: 0.61 cases/million/year; SCC: 0.13 cases/million/year). This remains consistent with Newton's incidence of SCC estimation [5], but it is still likely be an underestimate due to the possibility of underreporting of cases from other ophthalmology units.

From our data, there does not appear to be a dramatic change in the demographics of those affected by OSSN when compared to reports from 20 years ago. Older Caucasian men remain the most at risk group. Males were affected seven times as frequently as females. Epidemiological studies to date have suggested that there has been an increase in the incidence of OSSN in Africa, with patients being affected with more aggressive tumours at a younger age [11]. We were unable to detect any similar changes in the UK in this study. If HIV infection has a role in the development of OSSN in some cases, then the ready availability of anti-retroviral therapy in the UK might limit the impact of this infection in this part of the world.

In addition to the demographic risk factors, the data on risk factors were limited to the responses to the questions in the questionnaires. There was no specific question about levels of sunlight exposure because this was not thought to vary widely within the UK, and it was considered that it might be possible to make a better assessment of the impact of sunlight exposure by comparing the UK incidence of OSSN to that in a different geographical location with greater sunlight exposure, such as Australia. There were also no questions directly addressing atopy as a possible risk factor. There was, however, space on the baseline questionnaire for the reporting ophthalmologist to record any other risk factors that they thought might be relevant. Nothing was documented in this space on any of the returned questionnaires.

Although all the reporting ophthalmologists often commented on whether or not immunosuppression was a likely risk factor, information about other potential risk factors 
Table 3 Management of ocular surface squamous neoplasia cases as reported on baseline questionnaire

\begin{tabular}{|c|c|c|c|}
\hline Management & $\begin{array}{l}\text { All OSSN } \\
N(\%)\end{array}$ & $\begin{array}{l}\mathrm{CIN} \\
N(\%)\end{array}$ & $\begin{array}{l}\mathrm{SCC} \\
N(\%)\end{array}$ \\
\hline Number of cases & $34(100 \%)$ & $28(100 \%)$ & $5(100 \%)$ \\
\hline Referred from elsewhere & $17(50 \%)$ & $15(54 \%)$ & $2(40 \%)$ \\
\hline \multicolumn{4}{|l|}{$\begin{array}{l}\text { Treatment prior to seeing the } \\
\text { ophthalmologist reporting the case }\end{array}$} \\
\hline None & $17(50 \%)$ & $13(46 \%)$ & $3(60 \%)$ \\
\hline Topical lubricants alone & $1(3 \%)$ & $1(4 \%)$ & $0(0 \%)$ \\
\hline Topical antibiotics alone & $1(3 \%)$ & $0(0 \%)$ & $1(20 \%)$ \\
\hline Topical steroids alone & $2(6 \%)$ & $2(7 \%)$ & $0(0 \%)$ \\
\hline Excision alone & $8(24 \%)$ & $7(25 \%)$ & $1(20 \%)$ \\
\hline Excision and cryotherapy & $1(3 \%)$ & $1(4 \%)$ & $0(0 \%)$ \\
\hline Incisional biopsy & $4(12 \%)$ & $1(4 \%)$ & $0(0 \%)$ \\
\hline \multicolumn{4}{|l|}{$\begin{array}{l}\text { Initial treatment given by reporting } \\
\text { ophthalmologist }\end{array}$} \\
\hline Nil & $5(15 \%)$ & $5(18 \%)$ & $0(0 \%)$ \\
\hline $\begin{array}{l}\text { Biopsy and lymph node fine } \\
\text { needle aspiration }\end{array}$ & $1(3 \%)$ & $0(0 \%)$ & $1(20 \%)$ \\
\hline Topical antibiotics & $1(3 \%)$ & $0(0 \%)$ & $1(20 \%)$ \\
\hline Excision alone & $5(15 \%)$ & $5(18 \%)$ & $0(0 \%)$ \\
\hline Excision and mitomycin-C only & $1(3 \%)$ & $1(4 \%)$ & $0(0 \%)$ \\
\hline Excision and 5-fluorouracil only & $1(3 \%)$ & $1(4 \%)$ & $0(0 \%)$ \\
\hline $\begin{array}{l}\text { Excision and plaque radiotherapy } \\
\text { only }\end{array}$ & $1(3 \%)$ & $0(0 \%)$ & $1(20 \%)$ \\
\hline $\begin{array}{l}\text { Excision, cryotherapy, } \\
\text { mitomycin-C }\end{array}$ & $1(3 \%)$ & $1(4 \%)$ & $0(0 \%)$ \\
\hline $\begin{array}{l}\text { Excision with skin-sparing } \\
\text { exenteration, cryotherapy, } \\
\text { mitomycin-C }\end{array}$ & $1(3 \%)$ & $0(0 \%)$ & $1(20 \%)$ \\
\hline $\begin{array}{l}\text { Excision, cryotherapy, } \\
\text { mitomycin-C and amniotic } \\
\text { membrane graft }\end{array}$ & $3(9 \%)$ & $3(11 \%)$ & $0(0 \%)$ \\
\hline $\begin{array}{l}\text { Plaque radiotherapy and 5- } \\
\text { fluorouracil only }\end{array}$ & $1(3 \%)$ & $0(0 \%)$ & $1(20 \%)$ \\
\hline 5-Fluorouracil alone & $9(26 \%)$ & $9(32 \%)$ & $0(0 \%)$ \\
\hline Interferon alone & $3(9 \%)$ & $2(7 \%)$ & $0(0 \%)$ \\
\hline \multicolumn{4}{|l|}{ Adjunctive tests } \\
\hline None & $22(65 \%)$ & $20(71 \%)$ & $2(40 \%)$ \\
\hline \multicolumn{4}{|l|}{ HIV } \\
\hline Positive result & $0(0 \%)$ & $0(0 \%)$ & $0(0 \%)$ \\
\hline Negative result & $5(15 \%)$ & $4(14 \%)$ & $0(0 \%)$ \\
\hline \multicolumn{4}{|l|}{ HPV } \\
\hline Positive result & $2(6 \%)$ & $2(7 \%)$ & $0(0 \%)$ \\
\hline Negative result & $6(18 \%)$ & $3(11 \%)$ & $3(60 \%)$ \\
\hline Referred to elsewhere & $11(32 \%)$ & $7(25 \%)$ & $3(60 \%)$ \\
\hline
\end{tabular}

OSSN Ocular surface squamous neoplasia, CIN conjunctival intraepithelial neoplasia, SCC squamous cell carcinoma, HIV human immunodeficiency virus, $H P V$ human papilloma virus

ancludes one patient whose diagnosis was simply reported as "OSSN"

was frequently unavailable. It was therefore not possible to determine the real impact of cigarette smoking, HIV infection, or HPV infection. We did not expect routine measurement of p53 or p63 levels.

There was wide variation in the ways in which OSSN presented, particularly in the length of time between initial presentation with symptoms and/or signs of OSSN and receiving the histopathological diagnosis. The average
Table 4 Management in the 12 months since the first questionnaire was completed and clinical outcomes at the 12-month review

\begin{tabular}{|c|c|c|c|}
\hline Management or clinical outcome & $\begin{array}{l}\text { All OSSN } \\
N(\%)\end{array}$ & $\begin{array}{l}\text { CIN } \\
N(\%)\end{array}$ & $\begin{array}{l}\mathrm{SCC} \\
N(\%)\end{array}$ \\
\hline $\begin{array}{l}\text { Number of cases of OSSN with } 12- \\
\text { month follow-up data }\end{array}$ & $24(100 \%)$ & $22(100 \%)$ & $2(100 \%)$ \\
\hline \multicolumn{4}{|l|}{ BCVA (Snellen) } \\
\hline $6 / 6$ or better & $9(38 \%)$ & $8(36 \%)$ & $1(50 \%)$ \\
\hline $6 / 7.5$ & $4(17 \%)$ & $3(14 \%)$ & $1(50 \%)$ \\
\hline $6 / 9$ & $4(17 \%)$ & $4(18 \%)$ & $0(0 \%)$ \\
\hline $6 / 12$ & $3(12.5 \%)$ & $3(14 \%)$ & $0(0 \%)$ \\
\hline $6 / 15$ & $1(4 \%)$ & $0(0 \%)$ & $0(0 \%)$ \\
\hline $6 / 30$ & $2(8 \%)$ & $2(9 \%)$ & $0(0 \%)$ \\
\hline $6 / 60$ or worse & $1(4 \%)$ & $1(5 \%)$ & $0(0 \%)$ \\
\hline \multicolumn{4}{|l|}{$\begin{array}{l}\text { Additional treatment given since the } \\
\text { initial questionnaire was completed }\end{array}$} \\
\hline None & $13(54 \%)$ & $12(55 \%)$ & $1(50 \%)$ \\
\hline Excision only & $1(4 \%)$ & $1(5 \%)$ & $0(0 \%)$ \\
\hline Excision and 5-fluorouracil & $2(8 \%)$ & $2(9 \%)$ & $0(0 \%)$ \\
\hline Excision and plaque radiotherapy & $1(4 \%)$ & $1(5 \%)$ & $0(0 \%)$ \\
\hline Plaque radiotherapy alone & $1(4)$ & $0(0 \%)$ & $1(50 \%)$ \\
\hline Mitomycin- $\mathrm{C}$ and interferon & $1(4 \%)$ & $1(5 \%)$ & $0(0 \%)$ \\
\hline 5-Fluorouracil and interferon & $1(4 \%)$ & $1(5 \%)$ & $0(0 \%)$ \\
\hline Interferon alone & $4(17 \%)$ & $4(18 \%)$ & $0(0 \%)$ \\
\hline \multicolumn{4}{|l|}{ Complications of treatment } \\
\hline None recorded & $22(92 \%)$ & $20(91 \%)$ & $2(100 \%)$ \\
\hline Corneal ulcer & $1(4 \%)$ & $1(5 \%)$ & $0(0 \%)$ \\
\hline $\begin{array}{l}\text { Suspected allergy/inflammation } \\
\text { secondary to 5-fluorouracil }\end{array}$ & $1(4 \%)$ & $1(5 \%)$ & $0(0 \%)$ \\
\hline \multicolumn{4}{|l|}{ Clinical signs at 12 -month review ${ }^{\mathrm{a}}$} \\
\hline None & $10(42 \%)$ & $9(41 \%)$ & $1(50 \%)$ \\
\hline Redness/vascularisation & $3(12.5 \%)$ & $3(14 \%)$ & $0(0 \%)$ \\
\hline Conjunctival thinning & $1(4 \%)$ & $1(5 \%)$ & $0(0 \%)$ \\
\hline Conjunctival thickening & $2(8 \%)$ & $2(9 \%)$ & $0(0 \%)$ \\
\hline Conjunctival inclusion cysts & $1(4 \%)$ & $1(5 \%)$ & $0(0 \%)$ \\
\hline Corneal thinning & $1(4 \%)$ & $1(5 \%)$ & $0(0 \%)$ \\
\hline Corneal ulceration & $1(4 \%)$ & $1(5 \%)$ & $0(0 \%)$ \\
\hline "Metaplastic" corneal epithelium & $1(4 \%)$ & $1(5 \%)$ & $0(0 \%)$ \\
\hline $\begin{array}{l}\text { Scarring of the cornea or } \\
\text { conjunctiva }\end{array}$ & $9(38 \%)$ & $8(36 \%)$ & $1(50 \%)$ \\
\hline Symblepharon & $1(4 \%)$ & $0(0 \%)$ & $1(50 \%)$ \\
\hline \multicolumn{4}{|l|}{ Recurrence } \\
\hline Suspected & $3(12.5 \%)$ & $3(14 \%)$ & $0(0 \%)$ \\
\hline Confirmed & $2(8 \%)$ & $2(9 \%)$ & $0(0 \%)$ \\
\hline \multicolumn{4}{|l|}{ Time to next review } \\
\hline 1 month & $2(8 \%)$ & $2(9 \%)$ & $0(0 \%)$ \\
\hline 3 months & $4(17 \%)$ & $3(14 \%)$ & $1(50 \%)$ \\
\hline 4 months & $8(33 \%)$ & $7(32 \%)$ & $1(50 \%)$ \\
\hline 6 months & $8(33 \%)$ & $8(36 \%)$ & $0(0 \%)$ \\
\hline 12 months & $2(8 \%)$ & $2(9 \%)$ & $0(0 \%)$ \\
\hline
\end{tabular}

OSSN ocular surface squamous neoplasia, CIN conjunctival intraepithelial neoplasia, SCC squamous cell carcinoma, BCVA best corrected visual acuity

${ }^{\text {a}}$ Patients may have had more than one clinical sign of OSSN

length of time to diagnosis was over 7 months, and the impact of this delay in diagnosis is unclear. As has been reported in other studies, most cases were unilateral. Whilst the right eye was affected more frequently than the left eye 
in this study, this preponderance was not statistically significant and might be an artefact caused by low patient numbers. The distribution of the OSSN lesions suggests that the sun-exposed areas of the limbus and the nasal and temporal bulbar conjunctivae were affected more frequently than other sites. Although lesions on the right eye were larger than those on the left, they were not of higher histopathological grade. Both cortical cataract and skin cancer have been associated with asymmetrical ultraviolet light exposure with driving [44, 45]. Further studies would be needed to investigate whether asymmetrical exposure to ultraviolet light might be influencing the distribution of OSSN lesions in a similar way.

The most common form of treatment that was given by ophthalmologists who referred patients with OSSN elsewhere for tertiary care, prior to referring them onwards, was excision of the OSSN lesion. Other ophthalmologists opted for an incisional biopsy, or for topical treatment, prior to referring the patient to a tertiary unit for ongoing care. The range of treatments given by the reporting ophthalmologists was broad, and we were unable to identify a clear, systematic pattern for the selection of particular management plans. We can make the observation, however, that the primary treatment of OSSN frequently involved excision of the lesion, and interferon was a popular second-line treatment. Both of these approaches were used either alone or in conjunction with another form of treatment. Adjunctive tests were rarely performed but included confirming the patient's HIV status and testing the OSSN specimen for HPV.

Two patients had died within a year of their diagnosis of OSSN. We are unable to speculate as to their causes of death, but are conscious that OSSN, particularly in its more advanced stages may lead to death [46].

One patient who had previously been diagnosed with OSSN received an additional diagnosis of ocular mucous membrane pemphigoid. The co-existence of different ocular surface diseases with OSSN has been described previously, and can present additional challenges for the diagnostic process [47-49]. OSSN has also been reported to masquerade as other ocular surface conditions [50-52]. Whilst histopathology remains the gold standard for diagnosis, it has been suggested that there might be a role for noninvasive imaging modalities, such as high resolution optical coherence tomography, in the detection and differentiation of OSSN from other ocular surface pathologies [47].

Over two-thirds of the patients had visual acuity of $6 / 9$ or better at 12 months. Where reduced, this was mostly thought to be due to a comorbidity such as cataract. If the OSSN lesion involved the cornea, then this would clearly be more likely to impact vision than a superficial lesion confined to the conjunctiva. Occasionally, reduced visual acuity was thought to be a complication of the treatment given.
The range of treatments reported in this study differs slightly from those described by the UK national ocular oncology centre in Sheffield, where, for example, the first treatment options included photodynamic therapy but not plaque radiotherapy [41]. Differences might be related to local availability of equipment and expertise, as well as the case mix seen, that is, the severity of OSSN cases being treated. In addition, the availability of a wide range of potentially effective treatments contributes to the lack of consensus on optimal management. Both studies, however, show the popularity of excision, with or without additional treatment, as a first-line treatment in the UK. At their 12-month follow-up visit, two-thirds of patients had not required treatment beyond the first OSSN treatment given. In this study, every case where additional treatment was given was being managed in a tertiary care setting.

Although the number of reported complications of treatment was low, there is likely to be some overlap between the complications of treatment and the presence of clinical signs detected at the 12-month review.

Numerous factors, some of which could not reliably be assessed in this type of study, have been found to be associated with the risk of recurrence of OSSN [41, 53]. These include tumour size, first treatment given, tarsal location, histopathological grade, positive surgical excision margins and lack of adjunctive therapy. Recurrence of disease has been reported up to 11.5 years after surgical excision [2]. These patients therefore require lifelong monitoring. The two recurrences of OSSN confirmed in this study occurred in extensive lesions, but the maximum diameter was only provided for one of these lesions $(12 \mathrm{~mm})$. In the retrospective case series published by the national oncology centre in Sheffield, patients treated with mitomycin-C as the first-line of treatment were found to be the least likely to recur, but there was no statistically significant difference between the risk of recurrence in those treated with mitomycin-C first and those who were treated with excision first [41]. One of the two recurrences in our study had received first-line treatment with mitomycin-C and interferon, and the other, who had a background of previous immunosuppression, had been treated with excision and 5-fluorouracil. The confirmed recurrence rate was $6 \%$ at 12 months in this study, but may have been as high as $9 \%$ if one further suspected recurrence was confirmed. These rates are slightly lower than, but still comparable to, those of other published reports from a similar time-period [41, 53].

\section{Strengths and limitations}

This is the first nationwide study of the epidemiology of OSSN in the UK, in which all autonomous UK ophthalmologists involved in the direct care of patients with OSSN 
within the National Health Service had the opportunity to contribute via the BOSU reporting scheme. We set out to obtain presentation, management and 12-month follow-up information on incident cases presenting to secondary and tertiary care units across the country.

One limitation of this study is that most of the reporting ophthalmologists were based outside the four UK national ocular oncology centres, where it might be assumed that the majority of cases of OSSN are managed. Half of the cases that contributed to our analyses were, however, from tertiary units, which included ocular oncology centres and specialist cornea units. We were unable to capture information on any cases that were diagnosed with OSSN within the appropriate time frame but not reported via the BOSU scheme. Secondary and tertiary care for OSSN might differ in terms of the severity or complexity of pathology treated and the breadth of treatment modalities available.

The lack of data on 13 cases of OSSN that were identified, but for which the questionnaires were never filled, and the loss to follow-up of eight cases over the 12-month follow-up period are other relevant limitations, especially given the rarity of OSSN. We are unable to comment on the management or outcomes of these groups of patients, but if significantly different from the results reported then the relative proportion of patients in these categories could potentially change our observed findings.

\section{Treatment options for OSSN}

The variety of approaches to treatment reported in this study and the Sheffield case series [41] suggests that the management of individual patients depends, at least in part, on their initial point of contact with the ophthalmological services.

Whilst there are several accepted treatment pathways for OSSN there is no universally accepted gold standard [54]. Surgical excision using the "no touch" technique was the mainstay of treatment, but recurrence rates as high as $56 \%$ where surgical margins were positive for neoplasia, and $33 \%$ where margins were negative for neoplasia, have been reported [2]. Surgical excision is not recommended for large tumours due to the risks of limbal stem cell deficiency and/ or symblepharon formation [54]. Adjunctive cryotherapy has been shown to significantly reduce the risk of tumour recurrence in some studies [53].

In recent years, there has been a paradigm shift towards the use of topical/subconjunctival chemotherapy as either an adjunctive or primary therapy [4]. This has the benefit of treating the entire ocular surface, including clinically undetectable microscopic tumour spread. Mitomycin-C, 5fluorouracil and interferon alpha $2 b$ have all been shown to be highly effective and are now well-established therapies. Toxicity is, however, common, and the great variation in treatment regimes and a lack of direct comparison studies means that reported success and recurrence rates vary greatly [55]. Of the therapeutic agents, interferon has the best side effect profile but is expensive [55]. Used in conjunction with retinoic acid therapy it has been shown to result in clinical resolution in $98 \%$ of eyes, with a mean tumour-free follow-up period of 51 months [56]. Topical cidofovir has recently been shown to successfully treat refractory cases [57].

Published surveys conducted among physician members of the Ocular Microbiology and Immunology Group and the Cornea Society Listserv, Keranet, have demonstrated that chemotherapy is often employed as first-line therapy for OSSN $[4,58]$. However, a literature-based decision analysis model that was constructed to determine which of four treatment strategies (each involving surgery and/or interferon alpha $2 b$ therapy) minimised expected persistence or recurrence of OSSN suggested that surgical excision followed by interferon for positive surgical margins might be the best strategy [59]. There is a clear need for randomised controlled trials comparing the different treatment options [54].

\section{Generalisability and future work}

These results are specific to the UK population over the specified time-period, but the results might reflect a trend in populations with similar demographics, resources and risk factors for OSSN, for example, in a western European context.

In the future, a more precise estimate of the incidence of OSSN in the UK could come from working with ophthalmic pathologists who report on these cases, or from the use of routinely collected population-based cancer incidence data, although this has its own limitations. Whilst we were able to compare our findings to those reported by one UK ocular oncology centre [41], obtaining data more directly from more ocular oncology centres and specialist corneal units, where most patients with OSSN are seen, might provide further insights into the associations and outcomes of OSSN, as well as the full range of management options available. The ideal patient pathway and the rationale behind different approaches to treatment, possibly based on histopathologic features, suspected underlying risk factors, and evidence of clinical effectiveness, warrant further exploration as it seems unlikely that all the available options yield equally good results. A direct comparison with the risk factors, presentation, and outcomes of OSSN in the developing world could be informative, and it might be possible to further evaluate the effect of risk factors such as sunlight exposure via similar ophthalmological surveillance schemes in sunnier places such as Australia. 


\section{Summary}

\section{What was known before}

- Although older Caucasian men, particularly those living close to the equator, were thought to be at greatest risk of developing ocular surface squamous neoplasia (OSSN) in 2003, in recent years the epidemiology of this condition has been shown to be changing.

- OSSN affects people worldwide. In Africa, it has been affecting young people of both sexes with more aggressive tumours. The incidence of squamous cell carcinoma of the conjunctiva, a sub-category of OSSN was estimated to be $<0.2$ cases/million/year in the UK in 1996.

- There is a lack of consensus as to the optimal referral and treatment pathways for patients with histologically confirmed OSSN in the UK.

- To the best of our knowledge, an estimate of the incidence, associations, and outcomes of OSSN has not previously been determined in the UK using a national surveillance scheme that is accessible to all autonomous ophthalmologists practising within the national health service.

\section{What this study adds}

- This study found no compelling evidence of a change in the minimum incidence of OSSN in the UK, or its demographic profile, between 1996 and 2013-2014.

- The management of patients with OSSN in the UK varies widely.

- The most common primary treatment given for OSSN in this study was excision of the OSSN lesion, with or without adjunctive treatment.

- The most commonly reported secondary treatment was interferon. Reported complications of treatment were rare but occasionally severe. Recurrence within 12 months of follow-up occurred in at least $6 \%$ of patients.

\footnotetext{
Acknowledgements We would like to acknowledge and sincerely thank all the ophthalmologists who contributed to this study by reporting cases via the British Ophthalmological Surveillance Unit (BOSU) scheme. This work would not have been possible without their valuable input and support of this project. We would also like to express our gratitude to the BOSU and the Royal College of Ophthalmologists who provided us with this opportunity to study the epidemiology of ocular surface squamous neoplasia on a national scale.
}

Funding Funding for this study was obtained via a grant from the Oxfordshire Health Services Research Committee. This was supplemented by a grant that the British Ophthalmological Surveillance Unit holds from the Iris Fund for the Prevention of Blindness.

\section{Compliance with ethical standards}

Conflict of interest The authors declare that they have no conflict of interest.

\section{References}

1. Pizzarello LDJF. Bowen's disease of the conjunctiva: a misnomer. In: Jakobiec FA, editor. Ocular and adnexal tumours. Birmingham, AL: Aesculapius; 1978, p. 553-71.

2. Tabin G, Levin S, Snibson G, Loughnan M, Taylor H. Late recurrences and the necessity for long-term follow-up in corneal and conjunctival intraepithelial neoplasia. Ophthalmology. 1997;104:485-92.

3. Kiire CA, Srinivasan S, Karp CL. Ocular surface squamous neoplasia. Int Ophthalmol Clin. 2010;50:35-46.

4. Adler E, Turner JR, Stone DU. Ocular surface squamous neoplasia: a survey of changes in the standard of care from 2003 to 2012. Cornea. 2013;32:1558-61.

5. Newton R, Ferlay J, Reeves G, Beral V, Parkin DM. Effect of ambient solar ultraviolet radiation on incidence of squamous-cell carcinoma of the eye. Lancet. 1996;347:1450-1.

6. Ateenyi-Agaba C. Conjunctival squamous-cell carcinoma associated with HIV infection in Kampala, Uganda. Lancet. 1995;345:695-6.

7. Gichuhi S, Sagoo MS, Weiss HA, Burton MJ. Epidemiology of ocular surface squamous neoplasia in Africa. Trop Med Int Health. 2013;18:1424-43.

8. Masanganise R, Rusakaniko S, Makunike R, Hove M, Chokunonga $\mathrm{E}$, Borok $\mathrm{MZ}$, et al. A historical perspective of registered cases of malignant ocular tumors in Zimbabwe (1990 to 1999). Is HIV infection a factor? Cent Afr J Med. 2008;54:28-32.

9. Manderwad GP, Kannabiran C, Honavar SG, Vemuganti GK. Lack of association of high-risk human papillomavirus in ocular surface squamous neoplasia in India. Arch Pathol Lab Med. 2009; 133:1246-50.

10. Basti S, Macsai MS. Ocular surface squamous neoplasia: a review. Cornea. 2003;22:687-704.

11. Pola EC, Masanganise R, Rusakaniko S. The trend of ocular surface squamous neoplasia among ocular surface tumour biopsies submitted for histology from Sekuru Kaguvi Eye Unit, Harare between 1996 and 2000. Cent Afr J Med. 2003;49:1-4.

12. Kiire CA, Dhillon B. The aetiology and associations of conjunctival intraepithelial neoplasia. $\mathrm{Br} \mathrm{J}$ Ophthalmol. 2006;90:109-13.

13. Karp CL, Scott IU, Chang TS, Pflugfelder SC. Conjunctival intraepithelial neoplasia. A possible marker for human immunodeficiency virus infection? Arch Ophthalmol. 1996;114:257-61.

14. Cackett P, Gillies M, Leen C, Dhillon B. Conjunctival intraepithelial neoplasia in association with HIV infection. AIDS. 2005;19:351-2.

15. De Silva DJ, Tumuluri K, Joshi N. Conjunctival squamous cell carcinoma: atypical presentation of HIV. Clin Exp Ophthalmol. 2005;33:419-20.

16. Kabra RC, Khaitan IA. Comparative analysis of clinical factors associated with ocular surface squamous neoplasia in HIV infected and non HIV patients. J Clin Diagn Res. 2015;9:NC01-03.

17. Carreira H, Coutinho F, Carrilho C, Lunet N. HIV and HPV infections and ocular surface squamous neoplasia: systematic review and meta-analysis. Br J Cancer. 2013;109:1981-8. 
18. Waddell KM, Lewallen S, Lucas SB, Atenyi-Agaba C, Herrington CS, Liomba G. Carcinoma of the conjunctiva and HIV infection in Uganda and Malawi. Br J Ophthalmol. 1996;80:503-8.

19. Kaimbo Wa Kaimbo D, Parys-Van Ginderdeuren R, Missotten L. Conjunctival squamous cell carcinoma and intraepithelial neoplasia in AIDS patients in Congo Kinshasa. Bull Soc Belge Ophtalmol. 1998;268:135-41.

20. Timm A, Stropahl G, Schittkowski M, Sinzidi C, Kayembe D, Guthoff R. [Association of malignant tumors of the conjunctiva and HIV infection in Kinshasa (D. R. Congo). First results]. Ophthalmologe. 2004;101:1011-6.

21. Kaliki S, Kamal S, Fatima S. Ocular surface squamous neoplasia as the initial presenting sign of human immunodeficiency virus infection in 60 Asian Indian patients. Int Ophthalmol. 2017;37:1221-1228.

22. Steele KT, Steenhoff AP, Bisson GP, Nkomazana O. Ocular surface squamous neoplasia among HIV-infected patients in Botswana. S Afr Med J. 2015;105:379-83.

23. Gichuhi S, Macharia E, Kabiru J, Zindamoyen AM, Rono H, Ollando E, et al. Risk factors for ocular surface squamous neoplasia in Kenya: a case-control study. Trop Med Int Health. 2016;21:1522-30.

24. McClellan AJ, McClellan AL, Pezon CF, Karp CL, Feuer W, Galor A. Epidemiology of ocular surface squamous neoplasia in a veterans affairs population. Cornea. 2013;32:1354-8.

25. Chinogurei TS, Masanganise R, Rusakaniko S, Sibanda E. Ocular surface squamous neoplasia (OSSN) and human immunodeficiency virus at Sekuru Kaguvi Eye Unit in Zimbabwe: the role of operational research studies in a resource poor environment? Cent Afr J Med. 2006;52:56-58.

26. Afrogheh AH, Jakobiec FA, Hammon R, Grossniklaus HE, Rocco J, Lindeman NI, et al. Evaluation for high-risk HPV in squamous cell carcinomas and precursor lesions arising in the conjunctiva and lacrimal sac. Am J Surg Pathol. 2016;40:519-28.

27. Chauhan S, Sen S, Sharma A, Tandon R, Kashyap S, Pushker N, et al. American Joint Committee on cancer staging and clinicopathological high-risk predictors of ocular surface squamous neoplasia: a study from a tertiary eye center in India. Arch Pathol Lab Med. 2014;138:1488-94.

28. Ateenyi-Agaba C, Dai M, Le Calvez F, Katongole-Mbidde E, Smet A, Tommasino M, et al. TP53 mutations in squamous-cell carcinomas of the conjunctiva: evidence for UV-induced mutagenesis. Mutagenesis. 2004;19:399-401.

29. Auw-Haedrich C, Sundmacher R, Freudenberg N, Spelsberg H, Feltgen N, Maier P, et al. Expression of p63 in conjunctival intraepithelial neoplasia and squamous cell carcinoma. Graefes Arch Clin Exp Ophthalmol. 2006;244:96-103.

30. Mishra DK, Veena U, Kaliki S, Kethiri AR, Sangwan VS, Ali $\mathrm{MH}$, et al. Differential expression of stem cell markers in ocular surface squamous neoplasia. PLoS ONE. 2016;11:e0161800.

31. Napora C, Cohen EJ, Genvert GI, Presson AC, Arentsen JJ, Eagle $\mathrm{RC}$, et al. Factors associated with conjunctival intraepithelial neoplasia: a case control study. Ophthalmic Surg. 1990;21:27-30.

32. Flynn TH, Manzouri B, Tuft SJ. Ocular surface squamous neoplasia in an immunosuppressed patient with atopic keratoconjunctivitis. Int Ophthalmol. 2012;32:471-3.

33. Shome D, Honavar SG, Manderwad GP, Vemuganti GK. Ocular surface squamous neoplasia in a renal transplant recipient on immunosuppressive therapy. Eye. 2006;20:1413-4.

34. Shields CL, Ramasubramanian A, Mellen PL, Shields JA. Conjunctival squamous cell carcinoma arising in immunosuppressed patients (organ transplant, human immunodeficiency virus infection). Ophthalmology. 2011;118:2133-7.e2131.

35. Gupta N, Sachdev R, Tandon R. Ocular surface squamous neoplasia in xeroderma pigmentosum: clinical spectrum and outcome. Graefes Arch Clin Exp Ophthalmol. 2011;249:1217-21.
36. Kalamkar C, Radke N, Mukherjee A, Radke S. Xeroderma pigmentosum with bilateral ocular surface squamous neoplasia and review of the literature. BMJ Case Rep. 2016;2016: : bcr2016215364. Published 2016 May 10. https://doi.org/10.1136/ bcr-2016-215364.

37. Shah A, Espana EM, Singh AD. Ocular surface squamous neoplasia associated with atopic keratoconjunctivitis. Ocul Oncol Pathol. 2017;3:22-27.

38. Heinz C, Fanihagh F, Steuhl KP. Squamous cell carcinoma of the conjunctiva in patients with atopic eczema. Cornea. 2003;22:135-7.

39. Rundle P, Mudhar HS, Rennie I. Conjunctival intra-epithelial neoplasia occurring in young patients with asthma. Eye. 2010;24:1182-5.

40. Tiong T, Borooah S, Msosa J, Dean W, Smith C, Kambewa E, et al. Clinicopathological review of ocular surface squamous neoplasia in Malawi. Br J Ophthalmol. 2013;97:961-4.

41. Maudgil A, Patel T, Rundle P, Rennie IG, Mudhar HS. Ocular surface squamous neoplasia: analysis of 78 cases from a UK ocular oncology centre. Br J Ophthalmol. 2013;97:1520-4.

42. Foot B, Stanford M, Rahi J, Thompson J, British Ophthalmological Surveillance Unit Steering Committee. British ophthalmological surveillance unit steering C. The British Ophthalmological Surveillance Unit: an evaluation of the first 3 years. Eye. 2003;17:9-15.

43. Lee GA, Hirst LW. Incidence of ocular surface epithelial dysplasia in metropolitan Brisbane. A 10-year survey. Arch Ophthalmol. 1992;110:525-7.

44. Hirvela H, Luukinen H, Laatikainen L. Prevalence and risk factors of lens opacities in the elderley in Finland: a population based study. Ophthalmology. 1995;102:108-17.

45. Butler ST, Fosko SW. Increased prevalence of left-sided skin cancers. J Am Acad Dermatol. 2010;63:1006-10.

46. McKelvie PA, Daniell M, McNab A, Loughnan M, Santamaria JD. Squamous cell carcinoma of the conjunctiva: a series of 26 cases. Br J Ophthalmol. 2002;86:168-73.

47. Atallah M, Joag M, Galor A, Amescua G, Nanji A, Wang J, et al. Role of high resolution optical coherence tomography in diagnosing ocular surface squamous neoplasia with coexisting ocular surface diseases. Ocul Surf. 2017;15:688-95.

48. Hirst LW, Axelsen RA, Schwab I. Pterygium and associated ocular surface squamous neoplasia. Arch Ophthalmol. 2009;127:31-32.

49. Yeung SN, Kim P, Lichtinger A, Amiran MD, Cote E, Teitel S, et al. Incidence of ocular surface squamous neoplasia in pterygium specimens: an 8-year survey. Br J Ophthalmol. 2011;95:592.

50. Ganger A, Devi S, Gupta N, Vanathi M, Tandon R. Ocular surface squamous neoplasia masquerading as peripheral ulcerative keratitis. Trop Doct. 2017;47:233-6.

51. Sharma M, Sundar D, Vanathi M, Meel R, Kashyap S, Chawla R, et al. Invasive ocular surface squamous neoplasia masquerading as nodular scleritis. Ophthal Plast Reconstr Surg. 2017;33:e45-e47.

52. Moshirfar M, Khalifa YM, Kuo A, Davis D, Mamalis N. Ocular surface squamous neoplasia masquerading as superior limbic keratoconjunctivitis. Middle East Afr J Ophthalmol. 2011;18:74-76.

53. Galor A, Karp CL, Oellers P, Kao AA, Abdelaziz A, Feuer W, et al. Predictors of ocular surface squamous neoplasia recurrence after excisional surgery. Ophthalmology. 2012;119:1974-81.

54. Mills RA. Ocular surface squamous neoplasia: to cut or not to cut. Clin Exp Ophthalmol. 2014;42:307-8.

55. Nanji AA, Sayyad FE, Karp CL. Topical chemotherapy for ocular surface squamous neoplasia. Curr Opin Ophthalmol. 2013;24:336-42.

56. Krilis M, Tsang H, Coroneo M. Treatment of conjunctival and corneal epithelial neoplasia with retinoic acid and topical interferon alfa-2b: long term follow up. Ophthalmology. 2012;119:1969-73. 
57. Ip MH, George CR, Naing Z, Perlman EM, Rawlinson W, Coroneo MT. Topical cidofoivr for treatment-refractory ocular surface neoplasia. Ophthalmology. 2018;125:617-9.

58. Stone DU, Butt AL, Chodosh J. Ocular surface squamous neoplasia: a standard of care survey. Cornea. 2005;24:297-300.
59. Siedlecki AN, Tapp S, Tosteson AN, Larson RJ, Karp CL, Lietman T, et al. Surgery veinterferon alpha-2b treatment strategies for ocular surface squamous neoplasia: a literature-based decision analysis. Cornea. 2016;35: 613-8. 